\section{Arkivoc

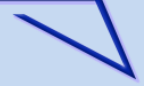

Archive for

Organic Chemistry
The Free Internet Journal

for Organic Chemistry
Review

Arkivoc 2017, part i, 26-40

\title{
Broadening the synthetic organic applications of Frustrated Lewis Pairs
}

\section{Sergey Arkhipenko and Andrew Whiting*}

Centre for Sustainable Chemical Processes, Department of Chemistry, Durham University, South Road, Durham, DH1 3LE, UK

Email: andy.whiting@durham.ac.uk

Received 09-06-2016

Accepted 10-23-2016

Published on line 12-04-2016

\begin{abstract}
Interactions between hindered Lewis acids and Lewis bases result in well-known frustrated Lewis pair behavior. Recent research has tended to concentrate on very hindered systems, resulting in high levels of activation, but not necessarily reactivity. In this article, we review the state-of-the-art and try to identify how FLP chemistry may develop further to give a wider range of applicable catalytic reactions, i.e. through softening both Lewis acid and base strengths, reducing hindrance and by controlling associative processes through tether length and dynamic effects.
\end{abstract}

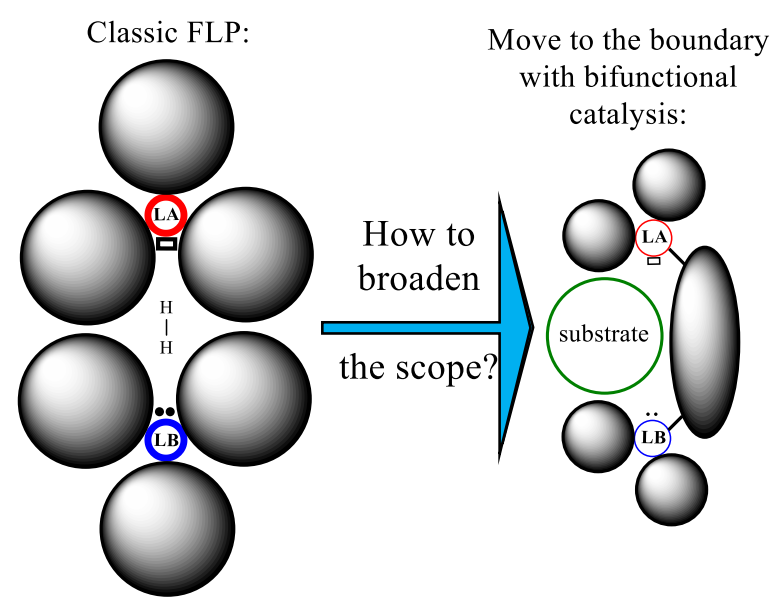

Keywords: Frustrated Lewis Pairs, bifunctional catalysis 


\section{Table of Contents}

1. Introduction

2. Separate Lewis Acids and Bases in Comparison with FLP Chemistry

3. "Frustration" and Reactivity of Lewis Pairs

4. Reactivity of Classic Lewis Adducts (CLAs)

5. Benefits of Reducing Lewis Acidity and Basicity

6. Other Approaches to Avoid Lewis Adduct Formation

7. Importance of Link between LA and LB Centers

8. Conclusion

References

\section{Introduction}

The discovery of new principles and concepts in science can be viewed from two different perspectives: 1 , how the new finding is different and separate from already existing data; and 2, how it is connected, and which place it occupies, in the established system of knowledge. In this light, any new discovery, to a certain extent, abstracts itself from the known by simply being novel. Unfortunately, this frequently leads to a degree of isolation of new research areas from previously discovered fields. However, progress often occurs through uniting principles, thus multiplying their potential. With this in mind, this article analyses the relatively novel field of Frustrated Lewis Pair (FLP) chemistry and attempts to put it into a wider context that encapsulates other areas and might impact the future of FLP chemistry.

Since the discovery of FLP behavior between hindered Lewis acids and Lewis bases, the underlying principles have been used in multiple areas of inorganic, organometallic and organic chemistry. Nevertheless, the majority of research in this field is still focused on developing significantly hindered, strongly Lewis acidic and basic catalysts, especially for the activation of small molecules. The concept of FLP ${ }^{1}$ emerged when Stephan et al. synthesized the bifunctional compound $1,{ }^{2}$ which contained both hindered, strong Lewis acid and base functions, and reversibly reacted with hydrogen, yielding the phosphonium borate salt $\mathbf{2}$ (Scheme 1). The steric inability of the Lewis acid (LA) and Lewis base (LB) to form adducts opened up the possibility to activate small molecules, ${ }^{3}$ which underwent asynchronously concerted, ${ }^{4}$ or stepwise, ${ }^{5}$ coordination to both LA and LB centers and subsequent heterolysis. Since their discovery, FLPs have been shown to be capable of reacting with a range of different substrates and perform various catalytic reactions. ${ }^{6}$ In addition, the FLP concept is beginning to be usefully viewed in context with previous research in the areas of bifunctional catalysis and organometallic chemistry. ${ }^{7}$ However, the goal of this review is to analyze how the scope of FLP applications could be increased by widening that context even further. Indeed, it can be suggested that softening Lewis acidity, basicity, steric requirements and tuning tether length between the components, is likely to lead to improved performance and hence, wider applications in organic chemical reactions.

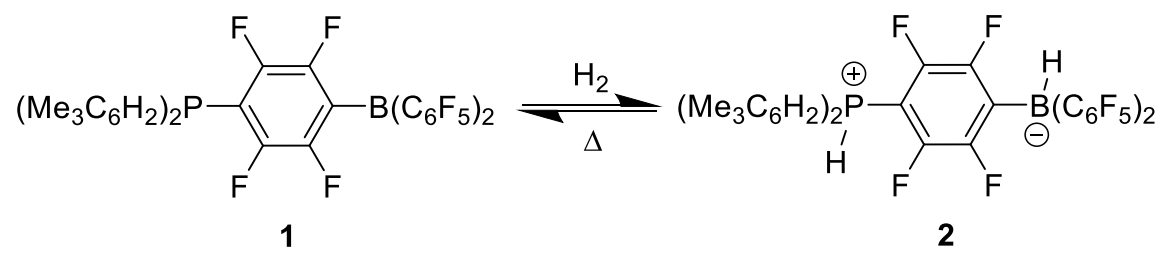

Scheme 1. Discovery of Frustrated Lewis Pairs reactivity. 


\section{Separate Lewis Acids and Bases in Comparison with FLP Chemistry}

Many of the existing FLP examples incorporate $\mathrm{B}\left(\mathrm{C}_{6} \mathrm{~F}_{5}\right)_{3}$ or its derivatives as the Lewis acid component. This borane has been intensely used ${ }^{8}$ in organic synthesis as a strong Lewis acid since its discovery, ${ }^{9}$ and it is important to investigate the parallels between FLP reactivity and reactions occurring with $B\left(C_{6} F_{5}\right)_{3}$ and its derivatives alone.

Reaction of dimethyl acetylenedicarboxylate (DMAD) 3 with 2 equivalents of $B\left(C_{6} F_{5}\right)_{3} 4$ proceeds via an unusual rearrangement through a cumulene intermediate $\mathbf{6}$, leading to product $\mathbf{7}$ (Scheme 2a). ${ }^{10}$ The intermediate, and the way it is formed, are reminiscent of a "traditional" FLP example of cyclic cumulene $\mathbf{1 1}$ formation from FLP 9 and ynone 8 (Scheme 2b). ${ }^{11}$ Similar 1,4-additions are shown as proceeding by two different pathways: 1) through initial coordination of the B species to the carbonyl oxygen with subsequent nucleophilic attack of the $\mathrm{C}_{6} \mathrm{~F}_{5}$ group onto the alkyne; or 2 ) initial nucleophilic attack of the $\mathrm{P}$ lone-pair onto the alkyne with the following stabilization of product to give cyclic compound 11 . However, it is also known, ${ }^{11}$ that ynone 8 reacts with $\mathrm{B}\left(\mathrm{C}_{6} \mathrm{~F}_{5}\right)_{3} 4$ to yield the stable, chelated species 12 (Scheme 2c), and subsequent treatment with ${ }^{\mathrm{t}} \mathrm{Bu}_{3} \mathrm{P}$ leads to the zwitterionic product 13. It seems, that the more electron-withdrawing carboxy substituent in intermediate 5 makes the nucleophilic attack of $\mathrm{C}_{6} \mathrm{~F}_{5}$ group on $s p$-carbon possible. In the case of a phenyl group, the chelated boron adduct $\mathbf{1 2}$ is stable unless a stronger nucleophile, ${ }^{\mathrm{t}} \mathrm{Bu} \mathrm{u}_{3} \mathrm{P}$, is introduced. These examples show the similarities in mechanisms of both free LA and FLP action.

a)

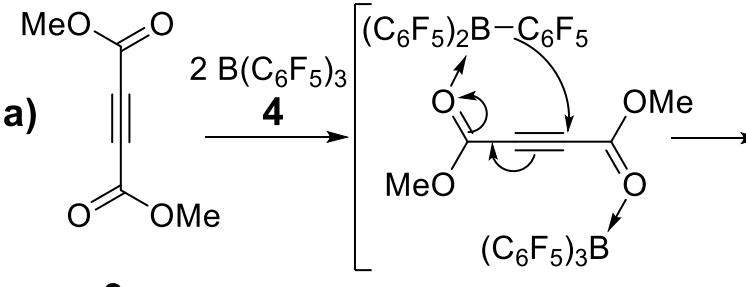

3

5

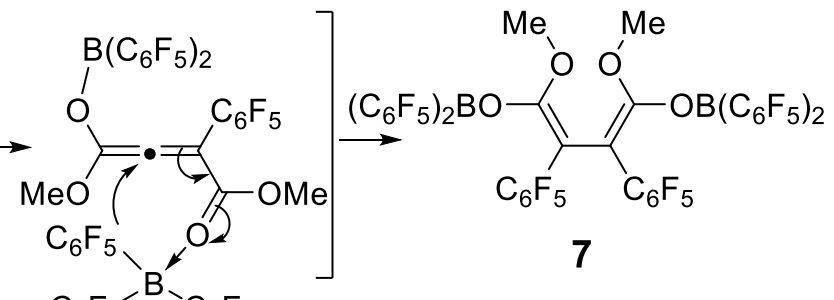
$\mathrm{C}_{6} \mathrm{~F}_{5}-\mathrm{B}^{-} \mathrm{C}_{6} \mathrm{~F}_{5}$ 6

b)

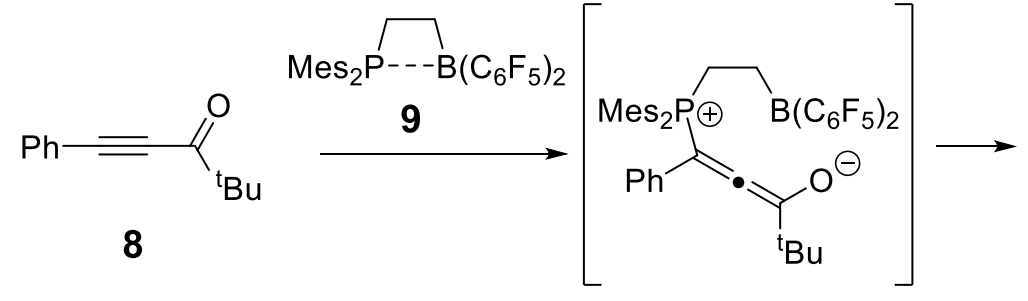

10

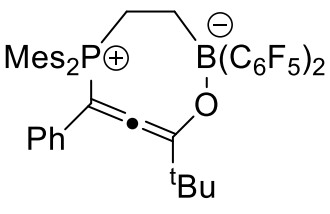

11

c)

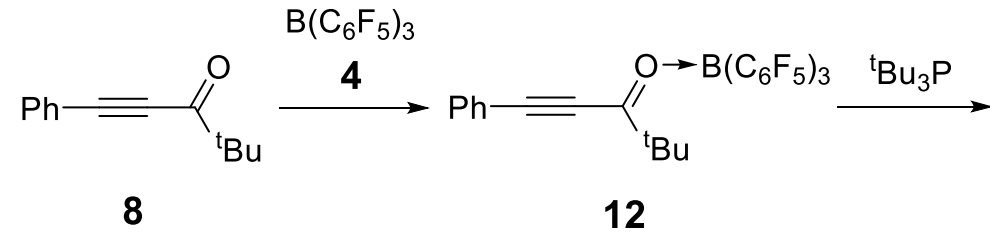

12

13

Scheme 2. Comparison of FLP and $B\left(C_{6} F_{5}\right)_{3}$ reactivity. ${ }^{10,11}$ 
FLPs are known to activate terminal $\mathrm{C}-\mathrm{H}$ bonds in alkynes, however, $\mathrm{B}\left(\mathrm{C}_{6} \mathrm{~F}_{5}\right)_{3}$ alone is known to show similar reactivity with some alkynes. ${ }^{12}$

Probably the most developed area of FLP reactivity is hydrogen activation and subsequent hydrogenations. It is important to mention that metal-free hydrogen activation has been achieved by LAs, namely anti-aromatic pentarylboroles alone, ${ }^{13}$ and this approach was extended to make the process reversible. $^{14}$

Hydrogen activation can also be achieved by a simple borane $\mathrm{HB}\left(\mathrm{C}_{6} \mathrm{~F}_{5}\right)_{2}$, which undergoes direct $[2+2] \sigma-$ bond metathesis ${ }^{15}$ by $\mathrm{H}_{2}$. This borane also catalyzes hydrogenation of olefins via hydroboration of the substrate, followed by hydrogenolysis of the $\mathrm{B}-\mathrm{H}$ bond. ${ }^{16}$

It has also been shown that in FLP-mediated $\mathrm{CO}_{2}$ reductions, the main role of activating substrates belongs to the LA component, ${ }^{17}$ though the LB plays a role in stabilizing the $\mathrm{FLP} \bullet \mathrm{CO}_{2}$ Complex. At the same time, the LB actually hinders hydride transfer by donating its lone pair to the LUMO of $\mathrm{CO}_{2}$, making it less electrophilic. It is also important to note that $\mathrm{CO}_{2}$ activation can be achieved in some cases by separate LBs, such as certain phosphines. ${ }^{18}$

However, sometimes true FLP behavior may not be immediately obvious, as the LB role can be played by the substrate itself, as in cases of hydrogenation of imines, ${ }^{19}$ amine-substituted benzenes ${ }^{20}$ and $\mathrm{N}$ heterocycles. ${ }^{21} \mathrm{Or}$, in fact even the solvent may be sufficiently nucleophilic. ${ }^{22}$

Such examples suggest that FLP systems sometimes perform similarly to individual LAs or LBs, thus, it is important to check the reactivity of substrates with the separate LAs and LBs, before making final conclusions on FLP behavior. Nevertheless, many studies unambiguously show that FLP reactivity cannot be observed without both the LA and LB present. For example, olefins do not react either with $B\left(C_{6} F_{5}\right)_{3}$ or with phosphines, ${ }^{23}$ however, 1,2-addition of the LA and LB to the olefin occurs when all three components are mixed together, and similar process is observed with dienes. ${ }^{24}$

\section{3. "Frustration" and Reactivity of Lewis Pairs}

One of the major and key features of FLP chemistry is the steric inability of the LA and LB to form a Lewis adduct, $^{3}$ often referred to as a classical Lewis adduct (CLA). However, while reducing the reactivity of the LA and LB towards each other, steric hindrance also limits substrate scope, since sterically more demanding molecules are less likely to be activated.

The main question when classifying Lewis pairs as either "frustrated" or "not frustrated" is where to draw the line that separates these terms. CLA formation is an equilibrium process, ${ }^{25}$ and thus there is both the adduct and separate LA and LB species present in solution. Catalytic activity of such systems will be kinetically determined, depending upon whether adduct dissociation, or LA-LB binding with substrate, or product dissociation or other reaction step is faster (Scheme 3). If the exchange between LA-LB adduct and the mixture of separate LA and LB is faster than the slowest step in the reaction, then even if the catalyst mainly exists in adduct form, it can still be active. Thus, CLA formation between LA and LB should not necessarily lead to a drop in catalytic performance of the FLP system. 


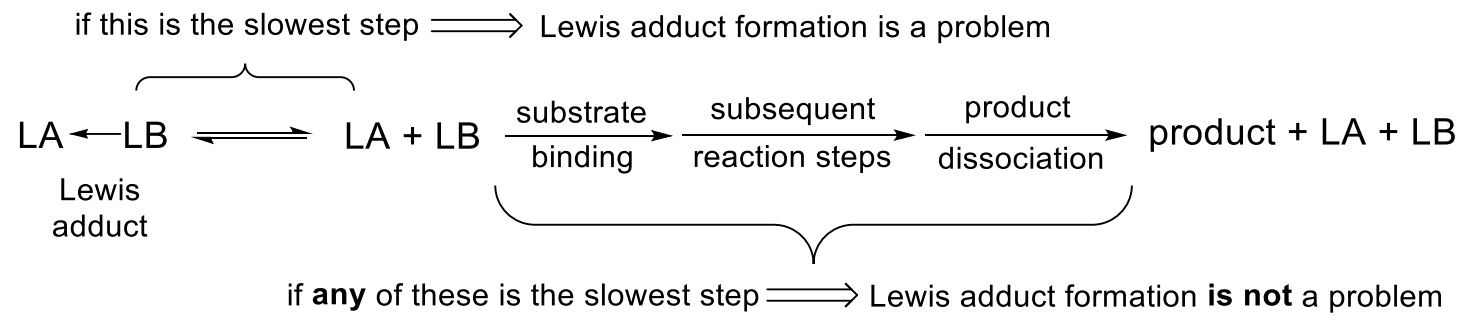

Scheme 3. Identifying when Lewis adduct formation has a negative impact on FLP activity.

These considerations are supported by multiple literature examples. It was found ${ }^{26}$ that a mixture of 2,6lutidine and $B\left(C_{6} F_{5}\right)_{3}$ can activate hydrogen and show typical FLP reactivity despite observing an equilibrium between the free LA and LB and the CLA by NMR. Indeed, the two reaction pathways are not mutually exclusive. Nevertheless, in this particular case, the activation of $\mathrm{H}_{2}$ was slower than with other bases, presumably due to the fact that some of both the LA and LB exist in an inactive state due to competitive CLA. ${ }^{27}$ However, the same $B\left(C_{6} F_{5}\right)_{3}-2,6$-lutidine system also activates $C_{2}$ faster than $B\left(C_{6} F_{5}\right)_{3}-2,2,6,6-$ tetramethylpiperidine, ${ }^{28}$ despite computational studies suggested that the latter combination of LA and LB should be a more reactive FLP system. ${ }^{29}$

From the thermodynamic point of view, it can be assumed that non-bonded LA and LB systems should in general bind to substrates better than CLAs, because the energy needed for adduct dissociation reduces reactivity. ${ }^{30}$ Nevertheless, CLAs are known to perform FLP chemistry through the equilibrium with free LA and LB in solution.

\section{Reactivity of Classic Lewis Adducts (CLAs)}

Other examples of $\mathrm{H}_{2}$ activation by mixtures of $\mathrm{B}\left(p-\mathrm{C}_{6} \mathrm{~F}_{4} \mathrm{H}\right)_{3}$ with different phosphines ${ }^{31}$ led to two important conclusions. Firstly, the stronger and more hindered bases tend to yield FLPs that bind hydrogen irreversibly and form phosphonium borate salts, and it is weaker basicity that becomes a requirement for liberation of hydrogen from the salts formed. The similar effect was observed for ansa-aminoboranes ${ }^{32}$ and was shown to be the result of reduced stability of ammonium hydridoborate formed, when a weaker Lewis basic component was used. Secondly, in many cases, CLAs have only been shown to be inactive towards $\mathrm{H}_{2}$ binding; the $\mathrm{H}-\mathrm{H}$ bond is particularly strong and thus, there is still a possibility for those adducts to activate lower energy bonds.

Alkynes react with both CLAs ${ }^{33}$ and cyclic double Lewis adducts, such as 14 (Scheme 4a). ${ }^{34}$ Complex 14 shows that breaking the two donor-acceptor bonds is possible and is driven by interaction with substrate resulting in complex 16. Similar activity is observed for Al-P dimer $\mathbf{1 7}$ which reacts with $\mathrm{CO}_{2}{ }^{35}$ and other small molecules (Scheme 4b). ${ }^{36} \mathrm{CO}_{2}$ can also be activated by $\mathrm{CLAs},{ }^{37}$ and indeed, as early as in $1978,{ }^{38}$ it was reported that for efficient catalysis, dimer formation of bifunctional species is actually preferred.

Both the structures of dimers 14 and 17 were identified by X-ray crystallography, and this leads to another important conclusion that is often overlooked, i.e. the existence of interactions between LA and LB centers in solid-state molecular structures of crystalline compounds does not necessarily mean that such species predominate in solution, or equally that this is indicative of the absence of an equilibrium with the free LA and LB. In fact, in some cases, this equilibrium cannot be observed, even by NMR spectroscopy. For example, a mixture of $\mathrm{B}\left(\mathrm{C}_{6} \mathrm{~F}_{5}\right)_{3}$ and $\mathrm{PPh}_{3}$ activated alkynes, ${ }^{39}$ however, NMR spectra of the mixture showed no presence of the adduct components. 
a)

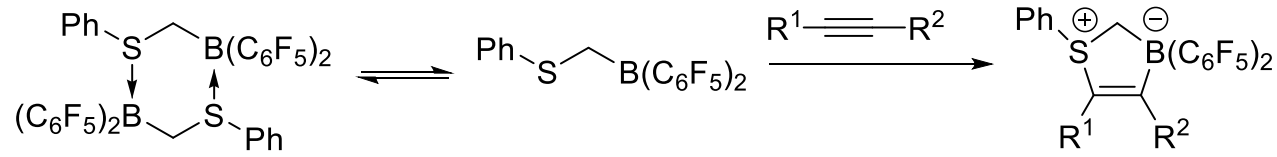

14

15

16

b)

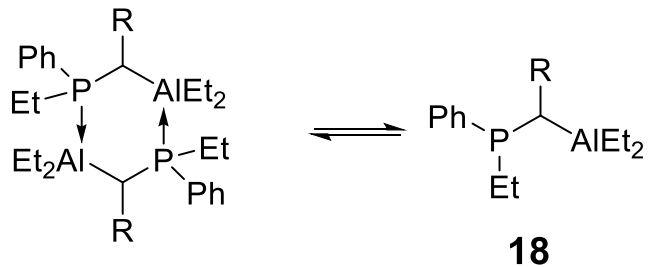

17

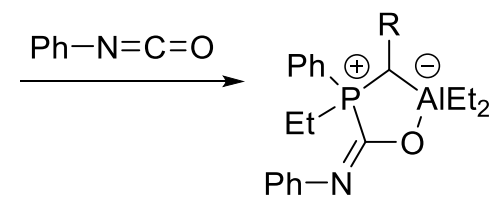

19 c)

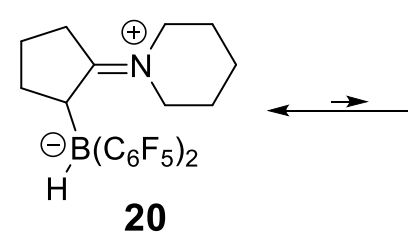

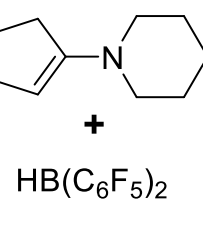

21

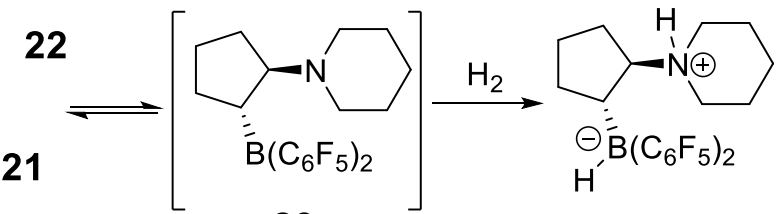

23

24

Scheme 4. FLP reactivity of LA-LB double adducts $14,{ }^{34} 17^{36}(a, b)$ and precursor compound $20^{42}(c)$ through equilibrium with free $L A$ and $L B$.

Following the same pattern, the weak adduct between $\mathrm{Et}_{3} \mathrm{P}$ and $\mathrm{B}\left(\mathrm{C}_{6} \mathrm{~F}_{5}\right)_{3}$ caused ring-opening of $\mathrm{THF}^{40}$ and the adduct of dimethylbenzylamine with $\mathrm{B}\left(\mathrm{C}_{6} \mathrm{~F}_{5}\right)_{3}$ reacted with $\mathrm{H}_{2}, \mathrm{CO}_{2}$, olefins, alkynes and diynes, again due to an equilibrium which makes free $L A$ and $L B$ available for reaction. ${ }^{41}$

A further demonstration of the importance of a facile $L A+L B-C L A$ equilibrium comes from observations of typical FLP reactivity of a precursor of a LA-LB system. ${ }^{25}$ The Piers borane $\mathbf{2 1}$ reacts with enamine $\mathbf{2 2}$ to give the iminium salt 20 (Scheme 4c), which was isolated and characterized by NMR and X-ray spectroscopy. ${ }^{42}$ However, exposure of $\mathbf{2 0}$ to dihydrogen causes precipitate of $\mathbf{2 4}$ within 5 minutes. This suggests that complex 20 exists in equilibrium with a mixture of free LA 21 and LB 22, which is also in equilibrium with a small amount of "invisible" hydroboration product $\mathbf{2 3}$. The bifunctional aminoborane $\mathbf{2 3}$ is a typical FLP, capable of binding $\mathrm{H}_{2}$ to yield 24.

CLAs can also catalyze polymerization reactions. ${ }^{43}$ Remarkably, the turnover frequency (TOF) for polymerization of $\gamma$-methyl- $\alpha$-methylene- $\gamma$-butyrolactone was shown to increase as the catalysts used were changed from FLPs to $\mathrm{CLA} \mathrm{Ph}_{3} \mathrm{P}-\mathrm{B}\left(\mathrm{C}_{6} \mathrm{~F}_{5}\right)_{3} .{ }^{44}$ Systems in which steric hindrance was too great were inactive in this type of polymerization reactions.

\section{Benefits of Reducing Lewis Acidity and Basicity}

It can now be seen that adduct formation does not necessarily lead to inactive FLP systems, and in many cases, conversely increases the performance of Lewis pairs. However, if the equilibrium with free species is slow or completely shifted to adduct, the Lewis pair system can indeed become inactive ${ }^{44,45}$. In these cases, reducing the likelihood of adduct formation can be achieved through increasing steric hindrance of both $L A$ and LB. Unfortunately, this approach can lead to loss of activity, as availability of both the LA and the LB drops. 
This also means that the scope of possible reactions which FLPs can catalyze also becomes limited by steric hindrance. Thus, another approach to avoid adduct formation can be the reduction of Lewis acidity and basicity of FLP components, reducing the strength of LA-LB complexation. This can result in achieving multiple other important goals.

Firstly, even though higher Lewis acidity and basicity can help accelerate substrate activation, it is the rate-determining step that should be considered for tuning LA and LB strength for a particular reaction. In general, high Lewis acidity and basicity slows down product dissociation from the catalyst. ${ }^{46}$ The adduct formed between Lewis acid and substrate, as in case of $\mathrm{CO}_{2}$ reduction ${ }^{47}$ or product, as with imine hydrogenations, ${ }^{48,49}$ can be sufficiently strong that its dissociation can become a rate-determining step. Using a weaker LA facilitates these reactions. Similarly, some FLPs can bind, for example, to benzaldehyde, forming a stable, and thus supposedly, inactive zwitterionic adduct. ${ }^{50}$

In the case of FLP-mediated hydrogenations, the rate-limiting step is not always the $\mathrm{H}_{2}$ activation, ${ }^{51}$ but can also be the hydrogen transfer. ${ }^{52}$ In cases where the rate determining step is the hydride transfer from borohydride, use of a weaker LA again improves performance of the catalyst. ${ }^{53}$ Following the similar pattern, $\mathrm{PhB}\left(\mathrm{C}_{6} \mathrm{~F}_{5}\right)_{2}$ was found to be more effective than $\mathrm{B}\left(\mathrm{C}_{6} \mathrm{~F}_{5}\right)_{3}$ in transferring the OR group to tin in allylstannylation reactions. ${ }^{54}$

Secondly, use of $\mathrm{B}\left(\mathrm{C}_{6} \mathrm{~F}_{5}\right)_{3}$, and some of its derivatives, may lead to undesirable ortho- or para-internal catalyst activation, ${ }^{55}$ to protonolysis of the facile $B-C_{6} F_{5}$ bond ${ }^{56,57}$ and migration of the pentafluorophenyl group in known 1,1- and 1,3-carboborations of terminal alkynes. ${ }^{12}$

Thirdly, the functional group ${ }^{58}$ and impurity ${ }^{59}$ tolerance of catalysts in FLP chemistry can in some cases be an issue. While there are strategies, such as the use of scavengers, that help to increase impurity tolerance, ${ }^{59}$ reducing the reactivity of LA and LB can also help to improve this aspect of FLP catalysts. Careful tuning of the Lewis acidity of the LA and steric requirements of both the LA and LB can even lead to FLP systems that are tolerant to water present in "bench" quality solvents. ${ }^{22}$

It is inspiring to see that these principles are becoming more generally recognized and applied. Introduction of two isopropyl groups onto nitrogen in weakly Lewis acidic and basic aminophenylboronic compound $\mathbf{2 7}$ is already enough to shift the equilibrium of adduct formation to uncoordinated species, ${ }^{60}$ allowing catalysis of amide formation (Scheme 5a), and similar reactivity is observed even for N,N-dimethyl derivative. ${ }^{61}$ Attempts have been made to reduce the basicity of the LB component of FLPs by the introduction of pentafluorophenyl substituents into the phosphines, which has provided compounds capable of good FLP reactivity. ${ }^{62}$ Dihydrogen cleavage was achieved with an "inverse" FLP between a strong LB and a weak LA. ${ }^{63}$ Dropping the Lewis acidity to the level of an aryl boronate, as in catalyst 29, still allowed activation and subsequent hydroboration of $\mathrm{CO}_{2}$ to take place (Scheme $5 \mathrm{~b}$ ); ${ }^{64}$ a result which again underlines the possibility of using weaker LAs and LBs. Catalyst 31 participated in $\mathrm{H}_{2}$ activation and provided a route to $\mathrm{CO}_{2}$ reduction (Scheme $5 c$ ), ${ }^{65}$ and even though it underwent protodeboronation to 32 in the process, the potential of using a non-fluorinated, weakly acidic triarylborane (LA) and unhindered dimethylarylamine (LB) for achieving FLP reactivity has been realized and is a promising development. 
a)

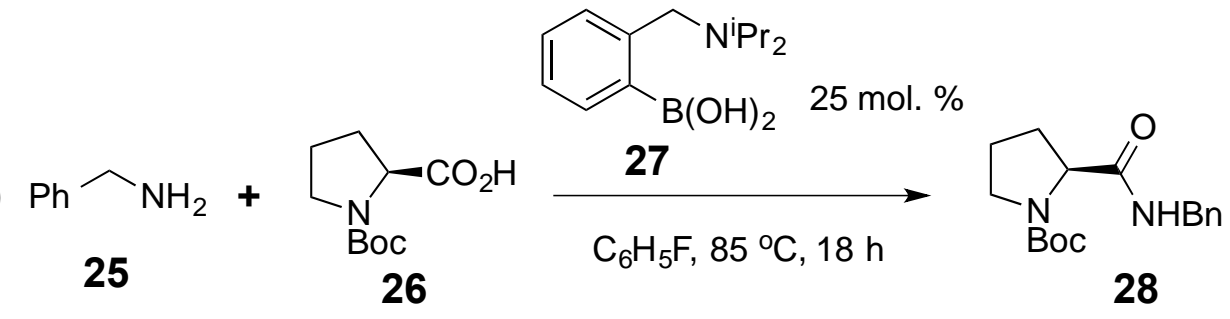

b)<smiles>Oc1ccccc1Pc1ccccc1</smiles>

29<smiles>O=P(O)(c1ccccc1)c1ccccc1Oc1ccccc1P(=O)(O)c1ccccc1</smiles>

30

c)

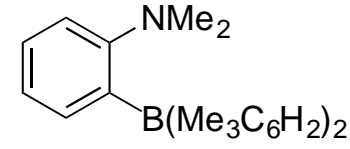

31

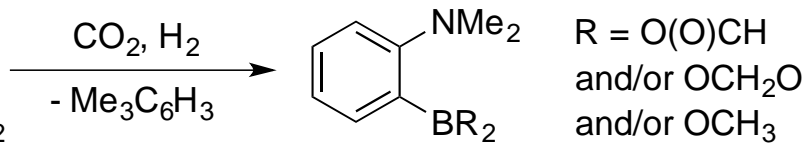

32

Scheme 5. Weakly Lewis-acidic, weakly hindered compounds performing "bifunctional" and/or "FLP-type" reactivity.

\section{Other Approaches to Avoid Lewis Adduct Formation}

Apart from reducing Lewis acidity and basicity, other methods of preventing Lewis adduct formation between LA and LB are known.

Possibly the most straightforward approach is simply to prevent contact between free $L A$ and $L B$, by for example, performing reactions in a stepwise manner. Pre-activation of substrate with the LA, followed by subsequent addition of the LB was used for polymerizing a divinyl monomer. ${ }^{66}$ The existence of a boraneolefin Van der Waals complex in the FLP-mediated reactions with alkenes ${ }^{67}$ and knowledge of the stepwise character of $\mathrm{N}_{2} \mathrm{O}$ capture by phosphine-borane $\mathrm{FLPs}^{, 68}$ also suggests that these reactions might be attempted stepwise. However, this approach can only be applied for non-interlinked FLPs.

Connecting the LA and LB centers with a carefully designed linkage can lead to a reduction in intramolecular adduct formation, ${ }^{69}$ however, the possibility for intermolecular coordination should always be considered.

The energy mismatch of LA and LB orbitals was presumed to enhance reactivity with $\mathrm{H}_{2} \cdot{ }^{70}$ Applying "electronic" rather than steric frustration was investigated for metal-ligand multiple-bond complexes, and reactivity similar to that of FLP systems was observed. ${ }^{71}$

Altering temperature is another tool for manipulating FLP reactivity. "Thermally induced frustration"72 can be observed, when the heating of adduct allows its dissociation and hence, FLP system can become active. ${ }^{73}$ The opposite situation was also reported, ${ }^{74}$ i.e. that adduct formation was shown to be irreversible at $\mathrm{RT}$, but that FLP reactivity could be observed at $-78^{\circ} \mathrm{C}$. An example of a photo-induced dissociation of a LA-LB adduct is also known. ${ }^{75}$ 
Increasing the $\mathrm{H}_{2}$ pressure has also been used to initiate its activation by using the unhindered combination of $\mathrm{Me}_{2} \mathrm{NH}$ and $\mathrm{BH}_{3}{ }^{76}$ This combination of $\mathrm{LA}$ and $\mathrm{LB}$ forms an adduct which is inactive to hydrogen at ambient pressures.

Solvent can play a role in stabilizing FLP adducts, by preventing adduct formation. ${ }^{77}$ In a different example, the introduction of a polyether macrocycle to a reaction medium did not prevent adduct formation, but resulted in stabilizing the product of $\mathrm{H}_{2}$ activation and thus facilitated this process. ${ }^{78}$

\section{Importance of Link between LA and LB Centers}

It is important to note that, according to definition, ${ }^{79}$ bifunctional catalysis is catalysis by bifunctional species, meaning all of the FLP consisting of separate LA and LB should rather be viewed as acting in concerted processes.

Catalysts with linked reaction sites lose less entropy when reacting with substrates than do unbound systems, ${ }^{29}$ which improves the reactivity of the connected FLPs ${ }^{64}$ and allows utilization of weaker LA and LB.

Tuning the tether type and length between the two reactive centers is known to have a major effect on bifunctional catalysis. Pyrrolidin-2-ylalkylboronic acids 35, 37 and 39 showed dramatically different reactivity as the length of alkyl chain between LA and LB centers was varied. ${ }^{80}$ Homoboroproline 35 was identified as efficient catalyst for enamine-mediated aldol formation with high enantiomeric selectivity (Scheme 6a). Increasing the carbon chain length by one methylene group in $\mathbf{3 7}$ led to a drop in reactivity and total loss of asymmetric induction (Scheme 6b), while increasing it further by one more $\mathrm{CH}_{2}$ in 39 completely switched off catalysis of single aldol formation, at the same time opening access to double aldol product (Scheme 6c).

a)<smiles>O=Cc1ccc([N+](=O)[O-])cc1</smiles>

33

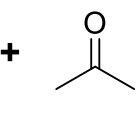

34

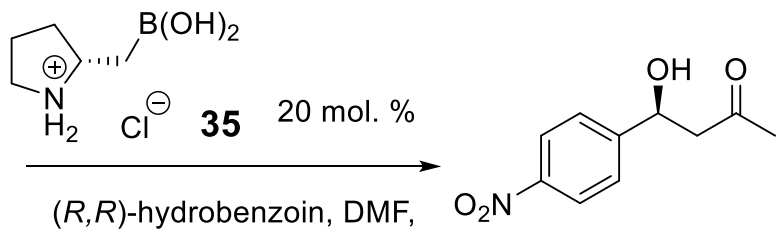

$\mathrm{Et}_{3} \mathrm{~N}, 3 \AA \mathrm{MS}, \mathrm{RT}, 6 \mathrm{~h}$

36, $88 \%, 95 \%$ ee

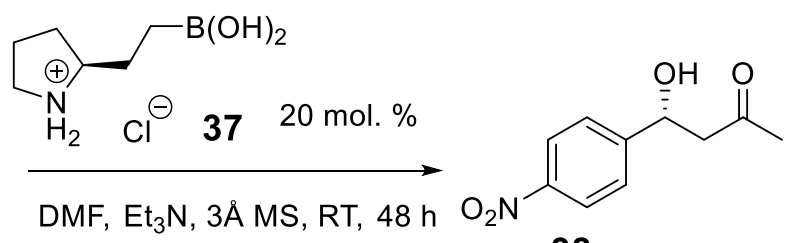

38, $21 \%, 1 \%$ ee

b)<smiles>CC(=O)[CH+]Cc1ccc([N+](=O)[O-])cc1</smiles>

33

34

33

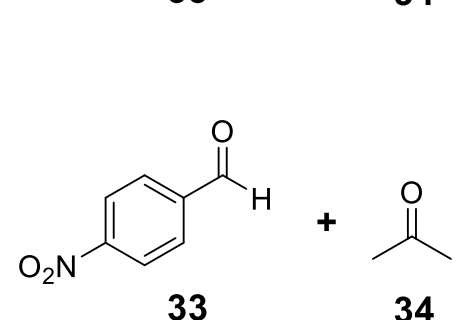

34

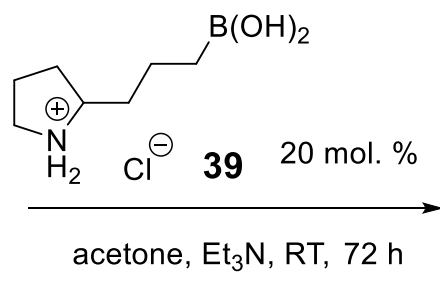

$\mathrm{O}_{2} \mathrm{~N}$<smiles>O=C(CC(O)c1ccc([N+](=O)[O-])cc1)CC(O)c1ccc([N+](=O)[O-])cc1</smiles>

$40,69 \%$

Scheme 6. Impact of tether length between LA and LB centers on reactivity. 
The same applies to FLP systems and for example, it was shown that similar geminal and vicinal P-B pairs show different reactivity towards cinnamaldehyde. ${ }^{81}$ Changing tether length between 2, 3 and 4 methylene groups had a major effect on FLP reactivity of phosphinoboranes. ${ }^{82}$ Preorganization of the LA and LB in geminal methylene-bridged phosphinoboranes allowed reactions with $\mathrm{H}_{2}$ and $\mathrm{CO}_{2}{ }^{30}$ even though two phenyl substituents on boron rendered LA center much less acidic than in well-studied pentafluorophenyl substituted boranes.

\section{Conclusion}

In conclusion, the performance of FLPs is not necessarily diminished by decreasing steric demand or LA and LB strength. In fact, reactivity can be tuned and certainly increased by that approach. Indeed, because Lewis adduct formation is always an equilibrium process, it can be proposed that subtlety of FLP design, i.e. introducing milder Lewis acidity and basicity, reducing hindrance and careful adjustment of tether length between reactive centers, should lead to improved selectivity, reactivity and a significantly increased scope of FLP applications.

\section{References}

1. Stephan, D. W. Org. Biomol. Chem. 2008, 6, 1535-1539. https://doi.org/10.1039/b802575b

2. Welch, G. C.; Juan, R. R. S.; Masuda, J. D.; Stephan, D. W. Science 2006, 314, 1124-1126. https://doi.org/10.1126/science.1134230

3. Stephan, D. W. Dalton Trans. 2009, 3129-3136.

https://doi.org/10.1039/b819621d

4. Mömming, C. M.; Frömel, S.; Kehr G.; Fröhlich R.; Grimme S.; Erker, G. J. Am. Chem. Soc. 2009, 131, 12280-12289.

https://doi.org/10.1021/ja903511s

5. Lu, Z.; Cheng, Z.; Chen, Z.; Weng, L.; Li, Z. H.; Wang, H. Angew. Chem. Int. Ed. 2011, 50, 12227-12231. https://doi.org/10.1002/anie.201104999

6. Stephan, D. W.; Erker, G. Angew. Chem. Int. Ed. 2015, 54, 6400-6441.

https://doi.org/10.1002/anie.201409800

7. Stephan, D. W. J. Am. Chem. Soc. 2015, 137, 10018-10032.

https://doi.org/10.1021/jacs.5b06794

8. Adonin, N. Yu.; Bardin, V. V. Russian Chemical Reviews. 2010, 79 (9), 757-785. https://doi.org/10.1070/RC2010v079n09ABEH004136

9. Massey, A. G.; Park, A. J. J. Organomet. Chem. 1964, 2, 245-250. https://doi.org/10.1016/S0022-328X(00)80518-5

10. Nakatsuka, H.; Fröhlich, R.; Kitamura, M.; Kehr G.; Erker, G. Eur. J. Inorg. Chem. 2012, 1163-1166. https://doi.org/10.1002/ejic.201101413

11. Xu, B.-H.; Kehr G.; Fröhlich, R.; Wibbeling, B.; Schirmer, B.; Grimme S.; Erker, G. Angew. Chem. Int. Ed. 2011, 50, 7183-7186. 
https://doi.org/10.1002/anie.201101051

12. Hansmann, M. M.; Melen, R. L.; Rominger, F.; Hashmi, A. S. K.; Stephan, D. W. J. Am. Chem. Soc. 2014, 136, 777-782.

https://doi.org/10.1021/ja4110842

13. Houghton, A. Y.; Karttunen, V. A.; Fan, C.; Piers, W. E.; Tuononen, H. M. J. Am. Chem. Soc. 2013, 135, 941947.

https://doi.org/10.1021/ja311842r

14. Houghton, A. Y.; Karttunen, V. A.; Piers, W. E.; Tuononen, H. M. Chem. Commun. 2014, 50, 1295-1298. https://doi.org/10.1039/C3CC48796B

15. Nikonov G. I.; Vyboishchikov, S. F.; Shirobokov, O. G. J. Am. Chem. Soc. 2012, 134, 5488-5491 (2012). https://doi.org/10.1021/ja300365s

16. Wang, Y.; Chen, W.; Lu, Z.; Li, Z. H.; Wang, H. Angew. Chem. Int. Ed. 2013, 52, 7496-7499. https://doi.org/10.1002/anie.201303500

17. Lim, C.-H.; Holder, A. M.; Hynes, J. T.; Musgrave, C. B. Inorg. Chem. 2013, 52, 10062-10066. https://doi.org/10.1021/ic4013729

18. Buss, F.; Mehlmann, P.; Mück-Lichtenfeld, C.; Bergander, K.; Dielmann, F. J. Am. Chem. Soc. 2016, 138, 1840-1843.

https://doi.org/10.1021/jacs.5b13116

19. Chen, D. J.; Klankermayer, J. Chem. Commun. 2008, 2130-2131.

20. Mahdi, T.; Heiden, Z. M.; Grimme, S.; Stephan, D. W. J. Am. Chem. Soc. 2012, 134, 4088-4091. https://doi.org/10.1021/ja300228a

21. Geier, S. J.; Chase, P. A.; Stephan, D.W. Chem. Commun. 2010, 46, 4884-4886. https://doi.org/10.1039/c0cc00719f

22. Gyömöre, Á.; Bakos, M.; Földes, T.; Pápai, I.; Domján, A.; Soós, T. ACS Catal. 2015, 5, 5366-5372. https://doi.org/10.1021/acscatal.5b01299

23. McCahill, J. S. J.; Welch, G. C.; Stephan, D. W. Angew. Chem. Int. Ed. 2007, 46, 4968-4971. https://doi.org/10.1002/anie.200701215

24. Ullrich, M.; Seto, K. S.-H.; Lough, A. J.; Stephan, D. W. Chem. Commun. 2009, 2335-2337. https://doi.org/10.1039/b901212e

25. Schwendemann, S.; Oishi, S.; Saito, S.; Fröhlich, R.; Kehr, G.; Erker, G. Chem. Asian J. 2013, 8, $212-217$. https://doi.org/10.1002/asia.201200776

26. Geier S. J.; Stephan, D. W. J. Am. Chem. Soc. 2009, 131, 3476-3477. https://doi.org/10.1021/ja900572x

27. Karkamkar, A.; Parab, K.; Camaioni, D. M.; Neiner, D.; Cho, H.; Nielsen, T. K.; Autrey, T. Dalton Trans. 2013, 42, 615-619. https://doi.org/10.1039/C2DT31628E

28. Tran, S. D.; Tronic, T. A.; Kaminsky, W.; Heinekey, D. M.; Mayer, J. M. Inorg. Chim. Acta. 2011, 369, 126132.

https://doi.org/10.1016/i.ica.2010.12.022

29. Rokob, T. A.; Hamza, A.; Pápai, I. J. Am. Chem. Soc. 2009, 131, 10701-10710. https://doi.org/10.1021/ja903878z

30. Bertini, F.; Lyaskovskyy, V.; Timmer, B. J. J.; de Kanter, F. J. J.; Lutz, M.; Ehlers, A. W.; Slootweg, J. C.; Lammertsma, K. J. Am. Chem.Soc. 2012, 134, 201-204. 
https://doi.org/10.1021/ja210214r

31. Ullrich, M.; Lough, A. J.; Stephan, D. W. Organometallics 2010, 29, 3647-3654.

https://doi.org/10.1021/om100563m

32. Chernichenko, K.; Nieger, M.; Leskelä, M.; Repo, T. Dalton Trans. 2012, 41, 9029-9032. https://doi.org/10.1039/c2dt30926b

33. Caputo, C. B.; Geier, S. J.; Ouyang, E. Y.; Kreitner, C.; Stephan, D. W. Dalton Trans. 2012, 41, 237-242. https://doi.org/10.1039/C1DT11196E

34. Tanur, C. A.; Stephan, D. W. Organometallics 2011, 30, 3652-3657. https://doi.org/10.1021/om200336t

35. Boudreau, J.; Courtemanche, M.-A.; Fontaine, F.-G. Chem. Commun. 2011, 47, 11131-11133. https://doi.org/10.1039/c1cc14641f

36. Roters, S.; Appelt, C.; Westenberg, H.; Hepp, A.; Slootweg, J. C.; Lammertsma, K.; Uhl, W. Dalton Trans. 2012, 41, 9033-9045.

https://doi.org/10.1039/c2dt30080j

37. Sgro, M. J.; Dömer, J.; Stephan, D. W. Chem. Commun. 2012, 48, 7253-7255.

https://doi.org/10.1039/c2cc33301e

38. Litvinenko, L. M.; Oleinik, N. M. Russian Chemical Reviews, 1978, 47 (5), 401-415. https://doi.org/10.1070/RC1978v047n05ABEH002226

39. Dureen, M. A.; Stephan, D. W. J. Am. Chem. Soc. 2009, 131, 8396-8397. https://doi.org/10.1021/ja903650w

40. Welch, G. C.; Prieto, R.; Dureen, M. A.; Lough, A. J.; Labeodan, O. A.; Höltrichter-Rössmann, T.; Stephan, D, W. Dalton Trans. 2009, 1559-1570. https://doi.org/10.1039/b814486a

41. Voss, T.; Mahdi, T.; Otten, E.; Fröhlich, R.; Kehr, G.; Stephan, D. W.; Erker, G. Organometallics 2012, 31, 2367-2378.

https://doi.org/10.1021/om300017u

42. Xu, B.-H.; Bussmann, K.; Fröhlich, R.; Daniliuc, C. G.; Brandenburg, J. G.; Grimme, S.; Kehr, G.; Erker, G. Organometallics 2013, 32, 6745-6752.

https://doi.org/10.1021/om4004225

43. Zhang, Y.; Miyake, G. M.; John, M. G.; Falivene, L.; Caporaso, L.; Cavallo, L.; Chen, E. Y.-X. Dalton Trans. 2012, 41, 9119-9134.

https://doi.org/10.1039/c2dt30427a

44. Xu, T.; Chen, E. Y.-X. J. Am. Chem. Soc. 2014, 136, 1774-1777. https://doi.org/10.1021/ja412445n

45. Geier, S. J.; Gille, A. L.; Gilbert, T. M.; Stephan, D. W. Inorg. Chem. 2009, 48, 10466-10474. https://doi.org/10.1021/ic901726b

46. Setoyama, T. Catalysis Today 2006, 116, 250-262.

https://doi.org/10.1016/i.cattod.2006.01.031

47. Zhao, X.; Stephan, D. W. Chem. Commun. 2011, 47, 1833-1835.

https://doi.org/10.1039/c0cc04791k

48. Chase, P. A.; Jurca, T.; Stephan, D.W. Chem. Commun. 2008, 1701-1703.

https://doi.org/10.1039/b718598g 
49. Sumerin, V.; Schulz, F.; Nieger, M.; Atsumi, M.; Wang, C.; Leskela, M.; Pyykko, P.; Repo, T.; Rieger, B. J. J. Organomet. Chem. 2009, 694, 2654-2660.

https://doi.org/10.1016/j.jorganchem.2009.03.023

50. Ekkert, O.; Kehr, G.; Daniliuc, C. G.; Fröhlich, R.; Wibbeling, B.; Petersen, J. L.; Erker, G. Z. Anorg. Allg. Chem. 2013, 639 (14), 2455-2462.

https://doi.org/10.1002/zaac.201300421

51. Greb, L.; Tussing, S.; Schirmer, B.; Oña-Burgos, P.; Kaupmees, K.; Lõkov, M.; Leito, I.; Grimme, S.; Paradies, J. Chem. Sci. 2013, 4, 2788-2796.

https://doi.org/10.1039/c3sc50347j

52. Chase, P. A.; Welch, G. C.; Jurca, T.; Stephan, D. W. Angew. Chem. Int. Ed. 2007, 46, 8050-8053. https://doi.org/10.1002/anie.200702908

53. Nicasio, J. A.; Steinberg, S.; Inés, B.; Alcarazo, M. Chem. Eur. J. 2013, 19, 11016-11020. https://doi.org/10.1002/chem.201301158

54. Morrison, D. J.; Piers, W. E. Org. Lett. 2003, 5, 2857-2860.

https://doi.org/10.1021/ol034928i

55. Zhao, X.; Gilbert, T. M.; Stephan D. W. Chem. Eur. J. 2010, 16, 10304-10308.

https://doi.org/10.1002/chem.201001575

56. Chernichenko, K.; Madarász, A.; Pápai, I.; Nieger, M.; Leskelä, M.; Repo, T. Nature Chemistry 2013, 5, 718-723.

https://doi.org/10.1038/nchem.1693

57. Dash, A. K.; Jordan, R. F. Organometallics 2002, 21, 777-779.

https://doi.org/10.1021/om010515e

58. Greb, L.; Daniliuc, C. G.; Bergander, K.; Paradies, J. Angew. Chem. Int. Ed. 2013, 52, 5876-5879. https://doi.org/10.1002/anie.201210175

59. Thomson, J. W.; Hatnean, J. A.; Hastie, J. J.; Pasternak, A.; Stephan, D. W.; Chase, P. A. Org. Process Res. Dev. 2013, 17, 1287-1292.

https://doi.org/10.1021/op4000847

60. Coghlan, S. W.; Giles, R. L.; Howard, J. A. K.; Patrick, L. G. F.; Probert, M. R.; Smith, G. E. Whiting, A. J. Organomet. Chem. 2005, 690, 4784-4793.

https://doi.org/10.1016/i.jorganchem.2005.07.108

61. Liu, S.; Yang, Y.; Liu, X.; Ferdousi, F. K.; Batsanov, A. S.; Whiting, A. Eur. J. Org. Chem. 2013, 5692-5700. https://doi.org/10.1002/ejoc.201300560

62. Rosorius, C.; Kehr, G.; Fröhlich, R.; Grimme, S.; Erker, G. J. Organomet. Chem. 2005, 690, 4784-4793. https://doi.org/10.1016/i.jorganchem.2005.07.108

63. Li, H.; Aquino, A. J. A.; Cordes, D. B.; Hung-Low, F.; Hase, W. L.; Krempner, C.; J. Am. Chem. Soc. 2013, 135, 16066-16069.

https://doi.org/10.1021/ja409330h

64. Courtemanche, M.-A.; Légaré, M.-A.; Maron, L.; Fontaine, F.-G. J. Am. Chem. Soc. 2014, 136, 1070810717.

https://doi.org/10.1021/ja5047846

65. Courtemanche, M.-A.; Pulis, A. P.; Rochette, É.; Légaré, M.-A.; Stephan, D. W.; Fontaine, F.-G. Chem. Commun. 2015, 51, 9797-9800. https://doi.org/10.1039/C5CC03072B 
66. Jia, Y.-B.; Ren, W.-M.; Liu, S.-J.; Xu, T.; Wang, Y.-B.; Lu, X.-B. ACS Macro Lett. 2014, 3, 896-899. https://doi.org/10.1021/mz500437y

67. Zhao, X.; Stephan, D. W. J. Am. Chem. Soc. 2011, 133, 12448-12450. https://doi.org/10.1021/ja205598k

68. Gilbert, T. M. Dalton Trans. 2012, 41, 9046-9055. https://doi.org/10.1039/c2dt30208j

69. Beckmann, J.; Hupf, E.; Lork, E.; Mebs, S. Inorg. Chem. 2013, 52, 11881-11888. https://doi.org/10.1021/ic401406k

70. Geier, S. J.; Gilbert, T. M.; Stephan, D. W. J. Am. Chem. Soc. 2008, 130, 12632-12633. https://doi.org/10.1021/ja805493y

71. Whited, M. T. Beilstein J. Org. Chem. 2012, 8, 1554-1563. https://doi.org/10.3762/bjoc.8.177

72. Rokob, T. A.; Hamza, A.; Stirling, A.; Pápai, I. J. Am. Chem. Soc. 2009, 131, 2029-2036. https://doi.org/10.1021/ja809125r

73. Jiang, C.; Blacque, O.; Fox, T.; Berke, H. Organometallics 2011, 30, 2117-2124. https://doi.org/10.1021/ja809125r

74. Palomas, D.; Holle, S.; Inés, B.; Bruns, H.; Goddard, R.; Alcarazo, M. Dalton Trans. 2012, 41, 9073-9082. https://doi.org/10.1039/c2dt30195d

75. Matsuo, K.; Saito, S.; Yamaguchi, S. J. Am. Chem. Soc. 2014, 136, 12580-12583. https://doi.org/10.1021/ja506980p

76. Potter, R. G.; Somayazulu, M.; Cody, G.; Hemley, R. J. J. Phys. Chem. C 2014, 118, 7280-7287. https://doi.org/10.1021/jp410193m

77. Cao, Y.; Nagle, J. K.; Wolf, M. O.; Patrick, B. O. J. Am. Chem. Soc. 2015, 137, 4888-4891. https://doi.org/10.1021/jacs.5b02078

78. Bhunya, S.; Paul, A. Chem. Eur. J. 2013, 19, 11541-11546. https://doi.org/10.1002/chem.201301029

79. Muller, P. Pure Appl. Chem. 1994, 66, 1077-1184. https://doi.org/10.1351/pac199466051077

80. Batsanov, A. S.; Georgiou, I.; Girling, P. R.; Pommier, L.; Shen, H. C.; Whiting, A. Asian J. Org. Chem. 2014, 3, 470-479.

https://doi.org/10.1002/ajoc.201300127

81. Stute, A.; Kehr, G.; Daniliuc, C. G.; Fröhlich, R.; Erker, G. Dalton Trans. 2013, 42, 4487-4499. https://doi.org/10.1039/c2dt32806b

82. Wang, X.; Kehr, G.; Daniliuc, C. G.; Erker, G. J. Am. Chem. Soc. 2014, 136, 3293-3303. https://doi.org/10.1021/ja413060u 


\section{Authors' Biographies}

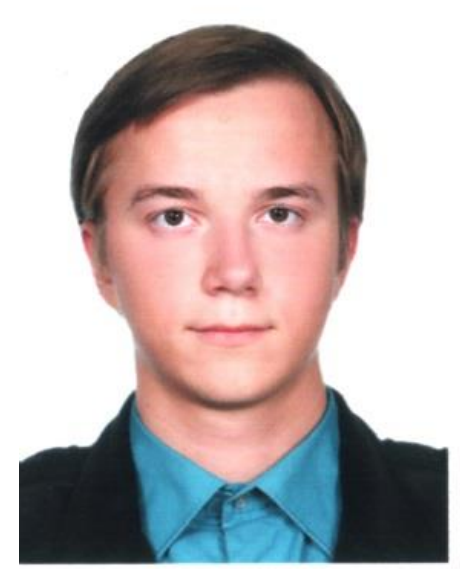

Sergey Arkhipenko graduated from Moscow State University (Specialist in Chemistry) in 2012 and in 2013 joined Whiting research group at Durham University, where he worked towards PhD, doing synthesis and studying bifunctional B-N catalysis, boron chemistry, and direct amide formation.

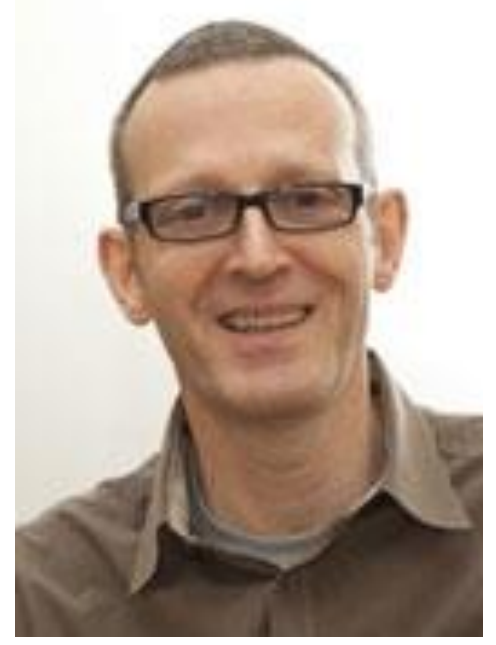

Prof. Andy Whiting completed his PhD at the University of Newcastle upon Tyne in 1984, working on ?-lactam chemistry with Prof. R. J. Stoodley, followed by post-doctoral research at Boston College, MA, USA, working on natural product synthesis and asymmetric synthesis with Prof. T. R. Kelly. After industrial experience with CibaGeigy, Central Research, he became Lecturer in Organic at UMIST in 1989, then moved to Durham University (2001) where he works on organoboron chemistry, asymmetric catalysis and developing new synthetic methodology. 